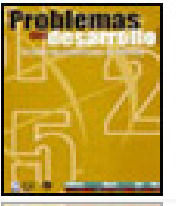

Problemas del Desarrollo. Revista Latinoamericana de Economía

ISSN: 0301-7036

revprode@servidor.unam.mx

Universidad Nacional Autónoma de México

México

Vázquez Sánchez, Jorge

EL COMPORTAMIENTO DEL PRECIO DE LAS ACCIONES Y RECESIÓN ECONÓMICA. EEUU Y MÉXICO

Problemas del Desarrollo. Revista Latinoamericana de Economía, vol. 41, núm. 160, enero-marzo, 2010, pp. 83-107

Universidad Nacional Autónoma de México

Distrito Federal, México

Disponible en: http://www.redalyc.org/articulo.oa?id=11820132005

Cómo citar el artículo

- Número completo

- Más información del artículo

Página de la revista en redalyc.org

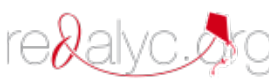

Sistema de Información Científica

Red de Revistas Científicas de América Latina, el Caribe, España y Portugal Proyecto académico sin fines de lucro, desarrollado bajo la iniciativa de acceso abierto 


\title{
EL COMPORTAMIENTO DEL PRECIO DE LAS ACCIONES Y RECESIÓN ECONÓMICA. EEUU Y MÉXICO
}

\author{
Jorge Vázquez Sánchez*
}

Fecha de recepción: 20 de octubre de 2009. Fecha de aceptación: 8 de febrero de 2010.

\section{Resumen}

En este artículo se hace un estudio de las correspondientes crisis en los Estados Unidos y en México, distinguiendo entre su aspecto financiero y el económico. Se enfocan las crisis financieras como ciclos naturales que pueden terminar en recesiones económicas, más o menos profundas, en cuyo caso estarían desempeñando una función profiláctica para eliminar el exceso de inversión generado durante la etapa de expansión. La intervención del Banco Central resulta muy importante para mitigar las restricciones de liquidez y de esa manera atemperar la depreciación de activos y, en su caso, la profundidad de la recesión. El estudio se sustenta en el modelo de la crisis financiera propuesto por Minsky y Kindleberger, así como en el análisis técnico del comportamiento del precio de las acciones.

Palabras clave: crisis financiera, recesión, sobreinversión, análisis técnico, precio de las acciones.

* Doctor en Finanzas Públicas. Profesor investigador de la Benemérita Universidad Autónoma de Puebla. Correo electrónico: jorgevazan232@yahoo.com.mx 
Abstract

This article studies the corresponding crises in the United States and Mexico, distinguishing between their financial and economic aspects. The focus is on financial crises as natural cycles that may end in more or less deep economic recessions, where they would perform a prophylactic function in eliminating excess investment generated during the expansion stage. The intervention of the Central Bank is very important in mitigating the restrictions on liquidity and in this way tempering the fall in asset prices and, when relevant, the depth of the recession. The study is based on the financial crisis model proposed by Minsky and Kindleberger, as well as the technical analysis of stock price behavior.

Key words: financial crisis, recession, over-investment, technical analysis, stock prices.

\section{Résumé}

Dans cet article, il est mené une étude des crises associées aux États-Unis et au Mexique en distinguant leurs aspects financier et économique. Les crises financières y sont vues comme des cycles naturels qui peuvent aboutir à des récessions économiques, plus ou moins profondes, auquel cas elles joueraient un rôle prophylactique en permettant d'éliminer l'excès d'investissement généré durant la période d'expansion. L'intervention de la Banque centrale s'avère très importante pour mitiger les restrictions de liquidité et, de cette manière, tempérer la dévaluation des actifs et, éventuellement, la gravité de la récession. Cette étude se base sur le modèle de la crise financière proposé par Minsky et Kindleberger, ainsi que sur l'analyse technique de l'évolution du prix des actions.

Mots clés: crise financière, récession, surinvestissement, analyse technique, prix des actions.

\section{Resumo}

Neste artigo faz-se um estudo das correspondentes crises nos Estados Unidos e no México, distinguindo entre seu aspecto financeiro e o econômico. Enfoca-se nas crises financeiras como ciclos naturais que podem terminar em recessões econômicas, mais ou menos profundas, em cujo caso estariam desempenhando uma função profilática para eliminar o excesso de inversão gerado durante a etapa de expansão. A intervenção do Banco Central resulta muito importante para mitigar as restrições de liquidez e dessa maneira atenuar a depreciação de ativos e, no caso, a profundidade da recessão. $O$ estudo sustenta-se no modelo da crise financeira proposto por Minsky e Kindleberger, bem como na análise técnica do comportamento do preço das ações.

Palavras-chave: crise financeira, recessão, superinvestimento, análise técnica, preço das ações. 


\section{Introducción}

1 desarrollo de la principal economía del mundo, los Estados Unidos, se ha carac-
terizado por el comportamiento cíclico. Recientemente, en el año 2001, ese país
experimentó una recesión que fue el colofón de un derrumbe financiero asociado al quiebre de la llamada nueva economía ${ }^{1}$. En ese proceso de expansión se presentó una sobreinversión en el sector de la tecnología internet, que fue eliminada mediante la caída de los precios accionarios de las empresas cotizadas en el Nasdaq.

Después de ese ciclo, el desarrollo económico americano se reimpulsó mediante otro ciclo de expansión que ha seguido la misma ruta de derrumbe financiero para eliminar el exceso de inversión, ahora en los sectores ligados a un boom inmobiliario.

Sin embargo, la reciente crisis ha sido muy violenta y ha tenido un alcance global, gran parte del mundo se ha sumido en el desorden financiero y en la recesión económica.

El ciclo de expansión-contracción puede ser analizado a través del comportamiento del precio de los valores, toda vez que su negociación refleja las condiciones de crédito y liquidez en los mercados financieros y sus valuaciones reflejan las expectativas económicas.

Una crisis precisamente comienza a percibirse cuando se presentan episodios de restricciones de liquidez y crédito, las que, de agudizarse, tienen el potencial de desvalorizar aceleradamente los activos y de precipitar una recesión económica.

El objetivo de este trabajo es analizar el ciclo de expansión-contracción de la economía americana visto a través del comportamiento del índice accionario Dow Jones Industrial Average (DJIA) ${ }^{2}$, así como su contagio a la economía mexicana. Teóricamente, el estudio se sustenta en el modelo de las crisis financieras de MinskyKindleberger y, empíricamente, en las herramientas del análisis técnico bursátil.

\section{El modelo de las crisis financieras}

La crisis financiera americana puede ser adecuadamente interpretada según el modelo planteado por Hyman Minsky y Charles P. Kindleberger. De acuerdo con dicho

1 De acuerdo con Joseph E. Stiglitz (2004), los noventa marcaron el inicio de lo que dio en llamarse la nueva economía, caracterizada por incrementos en productividad que duplicaban, o triplicaban, lo conocido durante las dos décadas precedentes.

2 El DJIA es un promedio ponderado de precios de 30 compañías industriales consideradas como blue chips que cotizan en el New York Stock Exchange (NYSE). Este índice sigue con bastante fiabilidad el comportamiento del mercado, dado que incluye a las empresas globales de mayor tamaño. 
modelo, una crisis financiera se desarrolla a través de las siguientes etapas: desplazamiento, sobreinversión (euforia compradora), malestar, crack bursátil y recesión económica (Kindleberger, 1992: 176-192).

En la fase de desplazamiento, diferentes factores logran abrir nuevas oportunidades de inversión en algún sector de la economía real, y son capaces de dinamizar todo el sistema, lo cual se expresa también en un impulso tanto del mercado accionario como del mercado de bonos; después sobreviene una euforia compradora de ambas clases de títulos; es ésta una etapa plenamente especulativa que se alimenta a sí misma atrayendo a nuevos inversionistas sobre la expectativa de que el boom continuará; la liquidez abunda y no hay problemas para hacer negocios. En esta etapa se ha generado un círculo virtuoso: la pujanza económica alimenta la especulación financiera y las ganancias de esta última actividad estimulan aún más la actividad económica; no obstante, el proceso se distorsiona cuando las ganancias especulativas sustentan un exceso de demanda que lleva a una situación de sobreinversión.

El boom especulativo es por sí mismo un fenómeno que tendrá que revertirse, los precios de mercado llegan a ser tan altos que en algún momento dejarán de ser realizables. Cuando se genera el sentimiento de que los rendimientos de los activos financieros se han estancado y empiezan a aparecer dudas sobre su sostenibilidad en el futuro, aparecen episodios de falta de liquidez en los que los inversionistas expertos se vuelven cada vez más selectivos en la compra de títulos. Esta fase se conoce como malestar financiero.

Los episodios de falta de liquidez en los mercados financieros obligan al Banco Central a intervenir en su función de prestamista de última instancia para proveer la liquidez necesaria y evitar el pánico financiero. Dependiendo de la magnitud de riqueza ficticia creada, la intervención de las autoridades monetarias aliviará el malestar o sólo administrará en lo posible la caída de los mercados. Kindleberger señala explícitamente que un fenómeno como la caída de una entidad bancaria o financiera importante llega a provocar el crack bursátil.

En tanto las ganancias de la especulación financiera alimenten la dinámica económica, desde la etapa de malestar la actividad económica comienza a resentir la caída del consumo interno; si éste es un componente importante del crecimiento económico, entonces un crack financiero tiene la capacidad de generar una recesión e incluso una depresión. La posibilidad del desarrollo de este último fenómeno otorga una gran relevancia a la intervención de las autoridades monetarias y fiscales de una nación, a fin de evitar que el derrumbe económico termine en una catástrofe.

El modelo Minsky-Kindleberger constituye una explicación de la dinámica cíclica del sistema económico y de sus fases, en las que puede distinguirse con claridad que 
la especulación anima un proceso de sobreinversión real que a la postre tiende a autocorregirse. En este proceso, la especulación incide sobre la inversión y el consumo, generando sendos procesos de expansión y contracción, los cuales son susceptibles de ser "administrados" por la autoridad monetaria, la que, sin embargo, puede actuar tardía o equivocadamente.

La especulación opera a través de un proceso de innovación financiera que hace crecer la liquidez y el crédito, y que logra financiarizar los activos reales, arrastrándolos hacia un proceso galopante de incremento de los precios de los activos. Sin embargo, el carácter especulativo de la subida de precios otorga un carácter ficticio a la creación de riqueza en los mercados financieros. Cuando los inversionistas deciden tomar ganancias de manera generalizada, se genera el pánico que hace desaparecer el exceso de riqueza financiera y la sobreinversión real.

El resto de este apartado se desarrollará al inicio del tercer apartado.

\section{El análisis técnico}

El análisis técnico es una herramienta que usa gráficas e indicadores para el estudio del comportamiento del precio de cualquier activo financiero, por ejemplo, las acciones y las monedas.

La suposición básica es que los inversionistas que participan en un mercado constituyen una masa que exhibe un comportamiento sistemático susceptible de ser analizado con fines de predicción.

El precio de un activo suele moverse sobre la base de las expectativas acerca de los fundamentos económicos del activo; en el caso de las acciones, por ejemplo, su precio incorpora las expectativas sobre el futuro de las ganancias de las empresas: buenas expectativas sustentan precios al alza, malas expectativas, los deprimen.

A partir del análisis técnico es posible establecer: tendencias, cambio de tendencias, figuras de alza, figuras de baja, momentos en los que el activo está sobrecomprado o sobrevendido. Con base en estas señales, los inversionistas compran y venden el activo o los activos en cuestión, con la finalidad de obtener ganancias especulativas.

Por supuesto que las conclusiones del análisis técnico no están exentas de riesgo, en realidad, las apreciaciones de los analistas técnicos suelen estar sujetas a la imprecisión propia de quien no tiene información cabal sobre el futuro, sin embargo, cuando se mira lo que ha sucedido, es decir cuando se mira el comportamiento pasado de los precios de un activo, el análisis técnico es muy útil para interpretar los patrones del comportamiento subyacentes. 
Para los inversionistas hay un elemento adicional de riesgo, asociado a la intensidad de las emociones con las que juzga las señales técnicas del comportamiento del precio del activo.

Las dos principales emociones subyacentes a la conducta del inversionista son la euforia y el miedo. Cuando el inversionista siente miedo tiende a vender, cuando siente euforia, tiende a comprar.

La euforia y el miedo son dos emociones básicas de gran importancia en la determinación del comportamiento del precio de un activo, suelen determinar el comportamiento cíclico del precio del activo a través de un fenómeno conocido como sobrerreacción.

Cuando hay buenas expectativas, los inversionistas comienzan a comprar, este comportamiento adquiere fuerza inercial debido a la creciente felicidad por las ganancias en alza, este proceso se convierte en una sobrecompra del activo debido a la euforia, hay aquí una sobrerreacción al alza, la cual, tarde o temprano, lleva a percibir que el precio del activo ha llegado muy alto y que en el futuro se desplomará, iniciándose así el movimiento contrario.

Cuando los inversionistas perciben que los precios han ido muy lejos, comienzan a vender para concretar ganancias. En el caso de que las buenas expectativas sigan vigentes, el proceso de ventas del activo se considera una toma de ganancias propia de una consolidación de la tendencia alcista de largo plazo, la cual seguirá hasta que se deterioren las expectativas sobre la economía.

Una vez que las expectativas económicas reflejan deterioro, se agudiza la venta del activo o los activos en cuestión; en este proceso se genera un temor creciente a las pérdidas. También en este caso, el miedo brinda fuerza inercial a la caída del precio del activo hasta llevar a situaciones de pánico en que los inversionistas venden para salvar su riqueza. En la caída de los mercados también hay una sobrerreacción, pero esta vez a la baja.

La sobrerreacción al alza o a la baja constituye un mecanismo de autorregulación que brinda señales a los inversionistas expertos de que los precios han llegado a ser demasiado altos o demasiado bajos y que es momento de vender o de comprar, según sea el caso.

De esta manera, el comportamiento del precio de un activo se da en ciclos, cada uno con su fase de alza y de baja, ciclos que pueden ser más o menos largos y que pueden contener en sí mismos otros ciclos de menor duración.

La masa de inversionistas está estratificada según su grado de conocimiento y experiencia en la compra de valores, el espectro abarca desde los inversionistas novatos 
que entran al mercado cuando está caro, hasta los inversionistas expertos, quienes aprovechan bien los movimientos cíclicos de los mercados.

El modelo Minsky-Kindleberger sobre las fases de las crisis financieras tiene su parangón en el análisis técnico. La fase de desplazamiento correspondería a una fase técnica conocida como acumulación, en la que inversionistas inteligentes van acumulando acciones baratas esperando el momento de despegue de los precios.

La fase de euforia correspondería a una fase técnica en la que se desarrolla una tendencia primaria de alza, conocida como tendencia bull, la cual es de largo plazo. Esta tendencia primaria tiene movimientos secundarios de corrección a la baja que sirven como procesos de consolidación de la tendencia primaria, es decir, son momentos en los que se toman ganancias y en los que la tendencia principal descansa.

La fase de malestar financiero según el modelo Minsky-Kindleberger corresponde a una fase técnica conocida como de distribución, en la que los inversionistas expertos se deshacen selectivamente del activo encarecido.

Una vez que el malestar madura, se precipita el cambio de tendencia primaria, de alza a baja, de bull a bear. El mercado bear ${ }^{3}$ es un mercado bajista en el que va consolidándose el pánico que lleva a episodios de ventas masivas del activo.

La tendencia bajista se precipita debido a que los inversionistas perciben que los precios son irrealmente altos y que no podrán sostenerse, es decir, el movimiento primario de alza crea riqueza ficticia que no podrá concretarse.

Lamentablemente, esta riqueza ficticia creada en los mercados financieros cuando experimentan un movimiento primario de alza sostiene una bonanza económica a través de un efecto riqueza sobre el consumo. Por este medio, también una crisis financiera se convierte en una crisis económica.

Cuadro 1

Fases de la crisis financiera

\begin{tabular}{|l|l|}
\hline \multicolumn{1}{|c|}{ Modelo Minsky-Kindleberger } & \multicolumn{1}{c|}{ Análisis técnico } \\
\hline Fase 1. Desplazamiento & Acumulación de acciones \\
\hline Fase 2. Sobredemanda o euforia & Tendencia primaria de alza (mercado bull) \\
\hline $\begin{array}{l}\text { Fase 3. Malestar } \\
\text { 3.1 Caída del Dow a territorio bear } \\
\text { 3.2 Recuperación asociada a la intervención de la Reserva Federal }\end{array}$ & Distribución de acciones \\
\hline Fase 4. Crack bursátil & Tendencia primaria de baja se agota y llega a soporte \\
\hline Fase 5. Recesión económica & Rebote del índice accionario \\
\hline
\end{tabular}

Fuente: Elaboración propia.

3 Se considera que un mercado entra en fase bear cuando el descenso en el precio del activo involucrado acumula un $20 \%$ desde su máximo histórico. 
En la tabla 1 establecemos la correspondencia entre las fases de la crisis financiera según el modelo Minsky-Kindleberger y las del análisis técnico:

En la tabla anterior puede verse con claridad que el análisis técnico constituye una herramienta para estudiar el ciclo financiero, no obstante, su potencial se centra en interpretar gráfica y estadísticamente el pasado, su capacidad prospectiva es limitada en tiempo y contenido.

Temporalmente la capacidad de predicción del análisis técnico se reduce a días y semanas; en cuanto a su contenido, no sustenta ninguna relación causal entre variables de ninguna índole. Desde el punto de vista técnico, en el presente todo lo que uno puede ver sobre el futuro son alternativas posibles sobre la posición de los indicadores técnicos, una de las cuales se concretará dependiendo del desenvolvimiento de los acontecimientos en la vida real y sus vinculaciones.

Por su parte, el modelo teórico al que recurrimos tiene una potencialidad mucho mayor, en tanto constituye una explicación plausible del ciclo financiero sobre la base de la vinculación entre variables económicas y financieras, específicamente, modela las fases del ciclo financiero como un proceso especulativo de sobreinversión que tiende a autorregularse.

\section{Las crisis financiera de los Estados Unidos}

En el caso americano, un boom en el sector inmobiliario fue el sustento de un boom financiero y de un acelerado crecimiento económico basado en el consumo interno y la inversión residencial. El crédito hipotecario barato ${ }^{4}$ y una creciente demanda de bienes raíces permitían a las familias americanas especular con casas y propiedades inmobiliarias 5 .

Por otro lado, la bonanza del crédito hipotecario sustentó el desarrollo de un amplio mercado de bonos a partir del desarrollo de algunas innovaciones, entre ellas, la bursatilización de las hipotecas ${ }^{6}$ y la aparición de algunos instrumentos de-

4 La tasa de los fondos federales se redujo de $6.5 \%$ en junio de 2000 a $1 \%$ en junio de 2003. Después se incrementó paulatinamente en 17 ocasiones, con 25 pb en cada una de ellas hasta un nivel de 5.25\% en junio de 2006, manteniéndose ahí hasta agosto de 2007. En septiembre de 2007 comenzó el ciclo de bajadas de la tasa de interés.

5 La gran demanda de casas y propiedades inmobiliarias empujaba rápidamente los precios, superando el valor de la hipoteca, por lo que resultaba rentable solicitar una segunda hipoteca sobre la base de la diferencia de valor.

$6 \quad$ Las bursatilizaciones hipotecarias también son conocidas como Borhis (Bonos respaldados por hipotecas), titularizaciones hipotecarias y MBS (Mortgage-Backed Securities). Constituyen 
rivados para la administración del riesgo que fueron utilizados como instrumentos de especulación? ${ }^{7}$.

La bonanza de las empresas dedicadas a la actividad inmobiliaria, la algarabía crediticia que favorecía el rendimiento de los bancos e instituciones financieras ligadas al crédito hipotecario, los excelentes rendimientos que lograban los magos de las finanzas en la banca de inversión estadounidense, así como la pujante actividad de las empresas de servicios y comercio al detalle, sustentaron el boom de las acciones.

El malestar se presentó cuando algunos de los factores que sustentaban el boom comenzaron a cambiar: los precios de las propiedades inmobiliarias habían llegado a niveles increíbles; se generó un exceso de crédito que tuvo como destinatarios a los sectores de población con mayor fragilidad socioeconómica, el sector subprime (Gómez-Tagle, 17/12/2007: 12); el crédito hipotecario había venido encareciéndose como resultado de un ciclo alcista de tasas de interés de la Reserva Federal americana y el mercado de bonos tenía un componente altamente especulativo.

Hacia finales de 2006, algunos indicadores señalaban la inminencia del fin del boom inmobiliario norteamericano ${ }^{8}$. Tempranamente, a principios de 2007, prominentes personalidades como Alan Greenspan, ex presidente de la Reserva Federal, y el magnate financiero George Soros señalaban los alcances recesivos de una inminente crisis financiera.

En 2007 aparecieron los primeros episodios de falta de liquidez en el mercado de bonos, sin embargo, gran parte de los especialistas consideraba que el deterioro estaba acotado temporalmente al sector subprime.

La mayoría de los miembros de la Reserva Federal también pensaba que la situación no derivaría en una crisis financiera, y se resistía a intervenir acosados por los fantasmas de la inflación y el riesgo moral. Finalmente, el Banco Central americano

instrumentos de deuda que tienen como respaldo un conjunto de créditos hipotecarios. De esta manera, el flujo de pagos de dichos instrumentos depende de los flujos del conjunto de hipotecas que respaldan la emisión. Existen tres tipos de bonos respaldados por hipotecas: 1) Mortgage Pass-Through, en los que un conjunto de hipotecas originadas por instituciones autorizadas son vendidas al mercado a través de un fideicomiso que emite los bonos. El bono refleja la vida del crédito hipotecario. 2) Collateralized Mortgage Obligations (CMO): se asemeja a la figura anterior, con la diferencia de que se estructura en diferentes clases o tranches (A, B, C, por ejemplo), en donde cada una tiene diferente duración (especificada en el prospecto), con la finalidad de disminuir el riesgo de prepago. 3) Stripped Mortgage-Backed Securities: se caracterizan por pagar el principal, interés y prepago con una disminución prorrata no equitativa a cada título de la deuda en circulación.

7 Tal fue el caso de los Credit Default Swaps (CDS) y los Collaterized Debt Obligation (CDO).

$8 \quad \mathrm{Al}$ respecto, véase La Caixa, 2007. 
tuvo que inyectar fuertes sumas de dinero para aliviar la crisis de liquidez e iniciar una agresivo ciclo de bajadas en la tasa de los fondos federales.

Sin embargo, la intervención de la Reserva Federal únicamente mitigó y prolongó el momento de la caída financiera que se presentó en septiembre de 2008 con la quiebra de Lehman Brothers, una importante institución de la banca de inversión?.

Las fases de la crisis financiera estadounidense, tal como se han descrito, pueden ser observadas en el comportamiento del DJIA (véase gráfica 1).

Gráfica 1

Índice Dow Jones EEUU enero 2004-marzo 2009

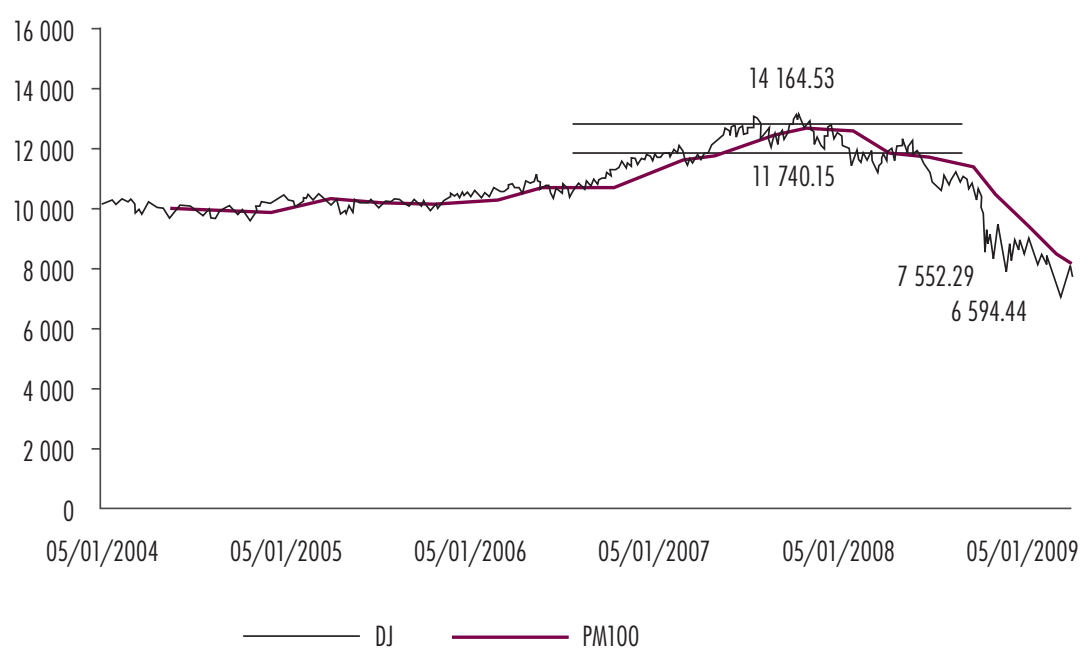

Fuente: Elaboración propia con datos tomados de mx.finance.yahoo.com/usindices.

\section{Fase 1. El desplazamiento}

El Dow Jones exhibe un periodo de lateralidad ${ }^{10}$ alrededor de los 10000 puntos entre 2004 y finales de 2005 aproximadamente, evidenciando una fase técnica de acumulación de acciones que corresponde a la fase de desplazamiento del modelo Minsky-Kindleberger.

9 El 14 de septiembre de 2008, Lehman Brothers Holding Inc., el cuarto Banco de Inversión de los Estados Unidos, solicitó al tribunal de quiebras protección contra sus acreedores. Los fondos de cobertura de riesgos con cuentas en dicho banco tuvieron que reconocer enormes pérdidas en acciones, bonos y materias primas (El financiero, 07/10/2008).

10 El precio de un activo o un índice de precios se mueve de manera lateral cuando sube y baja oscilando entre dos valores, los que no logra penetrar al alza o a la baja.

\section{Désarr. Prollo}




\section{Fase 2. La sobredemanda}

Esta fase dura aproximadamente del 27 de octubre de 2005 al 9 de octubre de 2007, fecha en la que el Dow Jones alcanzó su máximo histórico de 14164 puntos. El movimiento de alza o bull market puede visualizarse en la tendencia ascendente representada por el promedio móvil de 100 días (PM100). Esta fase se caracteriza por reforzamiento de las expectativas sobre la continuidad de la bonanza económica, la expansión de la liquidez y el crédito, lo que impulsa el precio de las acciones.

\section{Fase 3. El malestar}

\subsection{El Dow Jones entra en bear market}

El índice Dow Jones configura una cima con una fuerte resistencia ${ }^{11}$ en los 14164 puntos y un piso ${ }^{12}$ también fuerte en los $11740^{13}$ puntos, niveles que configuran un rectángulo de lateralidad, delimitado por las líneas horizontales de la gráfica. En el rectángulo de lateralidad pueden observarse dos cimas cuyos descensos se deben a la incipiente presencia de restricciones de liquidez y crédito.

El malestar se genera porque los inversionistas perciben que el ciclo de alza encuentra fuertes dificultades para proseguir, lo que los motiva a tomar ganancias de manera discrecional y selectiva. Ésta es una fase técnica de distribución de acciones.

El 10 de marzo de 2008 el DJ desciende a los 11740 puntos entrando a zona de bear market ${ }^{14}$. Durante esta etapa, el efecto de las restricciones de liquidez sobre los bancos es muy cuantioso, por ejemplo, Merrill Lynch $^{15}$ tomó enormes provisiones

11 Una resistencia constituye un límite en el proceso de alza de un índice, en el sentido de que cuando el índice alcanza la resistencia rebota a la baja. La resistencia es un valor de referencia en el que los inversionistas toman ganancias después de que el índice ha venido subiendo, esto es, en la resistencia la venta de acciones supera a la demanda. La resistencia se supera una vez que el índice lo intenta un número suficiente de veces, lo que depende de la fortaleza de la resistencia. Cuando la resistencia se supera, la compra de acciones supera por fin a la venta, y el índice podrá proseguir con su tendencia alcista.

12 Un piso o soporte constituye un límite en la caída de un índice accionario, porque cuando el índice llega al piso rebota al alza, debido a que en ese punto la demanda de acciones supera a la oferta. Después de intentarlo varias veces, el índice puede romper el piso y proseguir su tendencia de baja.

13 Valor del Dow Jones el día 22 de enero de 2007.

14 Se considera que un índice accionario entra en territorio bear cuando ha acumulado una caída de 20\% desde su máximo histórico. En el caso del Dow Jones, su máximo histórico es de 14164 puntos, cayó a 11740 puntos el 10 de marzo de 2008, acumulando una caída de 17 por ciento.

15 A pesar de sus esfuerzos por capitalizarse, la falta de liquidez ahogó a Merril Lynch; el 14 de marzo de 2008 tuvo que ser rescatado mediante una acción concertada entre la Reserva Federal y un importante banco de inversión privado. Los hechos posteriores mostraron que la Reserva 
por la crisis subprime, pero además tomó reservas adicionales por US $\$ 3000$ millones por posiciones aseguradas por el monoliner ACA y US $\$ 935$ millones más como reserva por contrapartes que potencialmente no pueden cumplir sus obligaciones (Suárez-Vélez, 2008).

En respuesta al descenso del DJ a territorio bear, en marzo de ese año la Reserva Federal redujo en $75 \mathrm{pb}$ su tasa de referencia, lo cual aceleró el ciclo de bajadas de la tasa de interés interbancaria, como medida para aliviar el estrés financiero.

\subsection{Recuperación asociada a la intervención de la Reserva Federal}

Esta fase se caracteriza por la recuperación del Dow Jones como resultado de la política de la Reserva Federal en dos frentes: un ciclo de reducciones agresivas de la tasa de referencia e intervenciones en los mercados monetarios para proveer liquidez ${ }^{16}$. Esta recuperación va del 11 de marzo de 2008 hasta los primeros días de mayo del mismo año, en los que alcanza poco más de 13000 puntos $^{17}$. Esta reacción alcista del DJ configura una tercera cima dentro del rectángulo de lateralidad.

Sin embargo, la intervención de la Reserva Federal no fue suficiente para detener el proceso de depreciación de los activos ligados a las hipotecas con sus consecuentes efectos perversos sobre las expectativas económicas y la salud de las empresas.

Ya en la etapa de malestar puede observarse con claridad el cambio de la tendencia primaria representada en el promedio móvil (PM90) de alza a baja, fenómeno que resulta ser irreversible.

\section{Fase 4. El crack bursátil}

\subsection{Desaparición de la banca de inversión}

El crack bursátil empieza a desarrollarse una vez que el DJ rompe a la baja el rectángulo de lateralidad. Esta fase se desarrolla entre el 9 de mayo y el 20 de noviembre

Federal actuó apropiadamente al rescatar a Merril Lynch, cancelando en ese momento la quiebra del sistema de banca de inversión, fenómeno que se presentó meses más tarde cuando la Reserva Federal se negó a rescatar a Lehman Brothers.

16 Tan sólo el 11 de marzo de 2008, la Reserva Federal tuvo que inyectar US \$200 000 millones de liquidez, actuando concertadamente con los bancos centrales de Canadá, Inglaterra y Suiza, así como el Banco Central Europeo, quienes en conjunto inyectaron US \$45 000 millones a sus mercados. En este caso, lo novedoso de la intervención de la Reserva Federal es que se trató de una especie de intercambio entre los valores del gobierno y deuda hipotecaria, incluso de baja calidad, otorgando liquidez a la cartera mala y mejorando por ello el balance de los bancos.

17 El 10 de marzo de 2008 el Dow Jones cayó a los 11740 puntos. 
de 2008, lapso en el que el Dow Jones cae desde los 13028 a los 7552.29 puntos, acumulando una pérdida de $47 \%$ respecto de su valor histórico alcanzado el 9 de octubre de 2007; corresponde a la fase bear del comportamiento del índice accionario americano, en la que el valor financiero se destruye aceleradamente como resultado de ventas masivas de valores. El crack bursátil fue precipitado por la quiebra de Lehman Brothers ${ }^{18}$, que originó cuantiosas pérdidas en acciones, bonos y materias primas a numerosos fondos de inversión que mantenían cuentas en esa correduría.

La crisis financiera ha significado un proceso de enormes depreciaciones de acti$\operatorname{vos}^{19}$, fusiones y rescates bancarios; en este proceso han sufrido duros golpes otrora poderosos bancos de inversión, grandes financieras hipotecarias y aseguradoras de bonos: New Century Financial Corp ${ }^{20}$, Countrywide Financial ${ }^{21}$, Fannie Mae, Freddie $\mathrm{Mac}^{22}$, Bear Stearms ${ }^{23}$, Indy Mac Bank ${ }^{24}$, Capital One Financial, Lehman Bros. Holdings, Morgan Stanley ${ }^{25}$, Goldman Sachs ${ }^{26}$, Merril Lynch ${ }^{27}$, Charles Schaw y Wachovia $^{28}$, Ambac Financial Group ${ }^{29}$.

18 Véase nota 9.

19 En agosto y septiembre de 2007, las depreciaciones de activos anunciadas fueron las siguientes: Wachovia, US \$1 300 millones; Merril Lynch, US \$1 400 millones; Countrywide, US \$1 000 millones; entre noviembre y diciembre de 2007, Morgan Stanley, US \$1 400 millones; Citigroup, US \$18 100 millones y Merrill Lynch, US \$16 000 millones.

20 A principios de abril de 2007, New Century Financial Corp solicita protección por bancarrota.

21 Countrywyde Financial otorgó préstamos por miles de millones de dólares a deudores que resultaron insolventes. Bank of America adquirió la firma cuando se dirigía a la bancarrota.

22 Poco antes de la quiebra de Lehman, el gobierno asumió el control de Fannie Mae y Freddie Mac, empresas de hipotecas constituidas con aval del gobierno federal. Estas financieras hipotecarias sucumbieron al incumplimiento de pago de hipotecas y al descenso de los precios de las viviendas.

23 JP Morgan compra Bear Stearms a principios de marzo de 2008.

24 A principios de 2008, la Fed. rescata a Indy Mac Bank.

25 El 6 de octubre de 2008, la Reserva Federal de los Estados Unidos aprobó la adquisición de hasta $24.9 \%$ de las acciones con voto de Morgan Stanley, por parte de Mitsubishi UFJ Financial Group.

26 A finales de septiembre de 2008, el gobierno tomó una medida extraordinaria al dar el visto bueno para convertir los bancos de inversión Morgan Stanley y Goldman Sachs en bancos tradicionales, con lo que puso a estas dos prestigiadas firmas bajo la supervisión de los reguladores bancarios estadounidenses, hecho que las ata a nuevos requerimientos de capital, más vigilancia y mucha menos rentabilidad de la que han disfrutado históricamente.

27 En el mismo mes de septiembre de 2008, Merrill Lynch fue vendida a Bank of America para evitar su quiebra.

28 En octubre de 2008, Wells Fargo \& Co acuerda comprar Wachovia.

29 El 5 de noviembre, la aseguradora Ambac reportó un importante aumento en sus pérdidas del tercer trimestre, afectada por fuertes amortizaciones de inversiones y un efecto negativo del desempeño del mercado. Los resultados trimestrales fueron golpeados por pérdidas no registradas de US \$2 700 millones de contratos de derivados crediticios. 
La primera gran oleada de la crisis, dirían los analistas financieros "la caída del primer zapato", se dio con la caída del Dow Jones por debajo de los 12000 puntos hacia terreno bear en el mes de marzo de 2008, enseguida vino una recuperación que se prolongó hasta el mes de mayo como resultado de las intervenciones de liquidez de la Reserva Federal y de su política de reducción de tasas; posteriormente prosiguió el descenso paulatino del Dow Jones en una tendencia bear que culminó en un crack; esta fase ha representado "la caída del segundo zapato".

La crisis financiera americana se convirtió en una gran depresión bursátil mundial: a principios de noviembre de 2008 Gran Bretaña había perdido 29.83\%; Alemania, 35.95\%; Francia, 35.55\%, e Islandia, 89.75\%. En Asia, China había perdido 66.54\%; Hong Kong, 46.64\%; Corea, 37.72\%, y Japón, 37.80\%. En América Latina, Argentina acumulaba una pérdida de $47.22 \%$; Brasil, $40.85 \%$, y México, $30.78 \%$ (El financiero, 06/11/2008: 3A).

Otra expresión de la magnitud de la crisis financiera es el incremento en los spread de CDS sobre bonos soberanos. A mediados de octubre de 2008, los gobiernos estadounidenses, europeos y japonés con otros de diversos países implantaron un rescate bancario y de otras instituciones, que consiste en asegurarles a los depositarios sus ahorros (en muchos casos al 100\%) y aportar billones de dólares de capital a una gran cantidad de instituciones financieras, además de proveer dinero al mercado para mantenerlo líquido. La enorme cantidad de dinero comprometido implica un aumento de la probabilidad de default de la deuda soberana, por lo tanto los premios de los CDS se incrementaron: el premio de CDS sobre Bonos del Tesoro ha aumentado de un punto base a principios de 2007 a 45 puntos (o sea US \$45 000 al año de prima). Los premios sobre CDS de la deuda inglesa, alemana, italiana y española están en alrededor de 64, 40, 105 y 112 puntos base, respectivamente, cuando a principios de 2007 estaban a dos o tres puntos para las dos primeras naciones. Para países como Argentina, los premios para el CDS están en cerca de 4000 puntos base, o sea US \$4 millones por cinco años, lo que es equivalente a la certeza de no pago en poco tiempo (El financiero, 07/11/2008: 7).

La caída de los mercados accionarios estadounidenses y europeos se da a medida que las instituciones financieras con fuertes posiciones en valores ligados a las hipotecas se ven obligadas a reconocer las menores valuaciones de los títulos.

4.2 Prolongación de la caída bursátil, dudas respecto de la solvencia de la banca comercial americana

La caída del Dow Jones a niveles de 7552.29 puntos el 20 de noviembre de 2008, expresión de la quiebra de la banca de inversión estadounidense, se prolongó hasta 
el 5 de marzo de 2009, cuando bajó hasta los 6594.44 puntos. Esta caída se debió a la incertidumbre de los mercados en relación con los planes gubernamentales respecto de los activos tóxicos ${ }^{30}$ y sus efectos en la salud de los bancos comerciales. La intención del gobierno de someter a estas instituciones a pruebas de estrés extremo para valorar su resistencia y sus necesidades de capitalización generó la incertidumbre mencionada. En este entorno, la expectativa de una inminente nacionalización de algunas entidades bancarias importantes sometió a los inversionistas a una gran tensión. Finalmente, hacia los primeros días de marzo, la inyección de capital público a Citibank con la declaración gubernamental de que los bancos no serían nacionalizados, así como el anuncio de City de que en enero y febrero el banco había obtenido buenas ganancias, terminó con el periodo de turbulencia financiera.

\section{Fase 5. Recesión económica}

Sin duda alguna, el largo periodo y la profundidad de las restricciones de liquidez y crédito en los mercados americanos y su efecto negativo sobre la actividad de los negocios y sus perspectivas, así como la gran destrucción de riqueza que ha acompañado a todo este proceso terminaron por generar una profunda recesión económica; la inversión residencial se desplomó afectando al consumo personal y al Producto Interno Bruto Americano (véase gráfica 2). La recesión estadounidense fue reconocida oficialmente el $1^{\circ}$ de diciembre de $2008^{31}$.

\section{El derrumbe financiero mexicano}

Hacia 2007 México estaba posicionado como un país con una bien cimentada estabilidad económica: desde el año 2000 se había obtenido el grado de inversión ${ }^{32}$, los gobiernos neoliberales en México pusieron especial interés en lograr equilibrio presupuestal; el Tratado de Libre Comercio (TLC) logró impulsar las exportaciones; las cuentas externas también se vieron beneficiadas por las exportaciones de crudo

30 Créditos e inversiones en manos de bancos, aseguradoras y fondos de inversión, cuya recuperación a corto plazo es dudosa.

31 El $1^{\circ}$ de diciembre de 2008, el National Bureau of Economic Research (NBER) hizo oficial la recesión de la economía de los EEUU, y reconoció que los síntomas se habían presentado desde el $1^{\circ}$ de enero de 2007. La noticia desplomó al Dow Jones en un 7.7 por ciento.

32 Moody's otorgó a México el grado de inversión (Baa3) en marzo de 2001. Por su parte, la calificadora Standard \& Poor's no la otorgó hasta 2002 (BBB-); en 2005 esta calificadora mejoró la calificación a BBB y en 2008 a BBB+. 
Gráfica 2

Producto Doméstico Bruto (GDP), Gastos de Consumo Personal (GCP) e inversión privada (IDPBR) de EEUU. Tasas de cambio porcentual analizadas. Trimestres 2004-1 a 2009-2

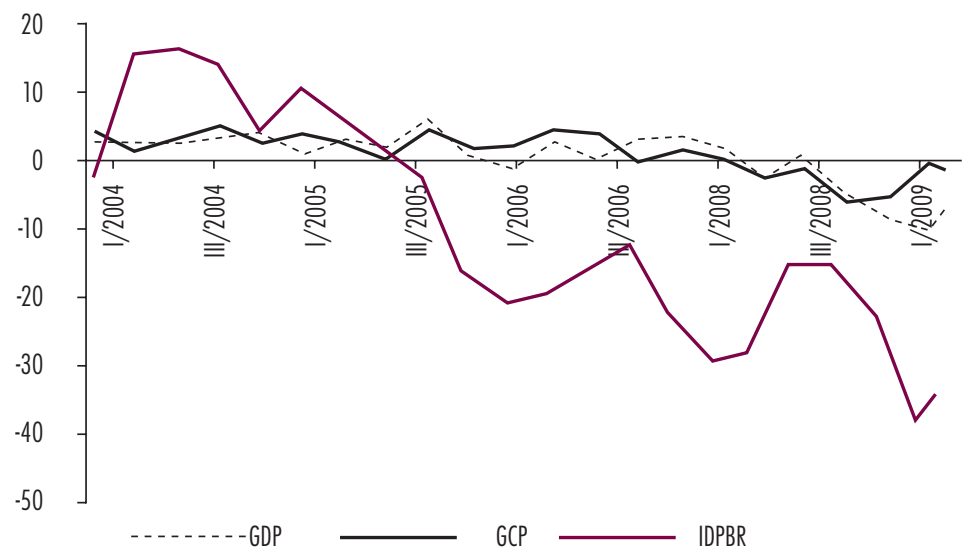

Fuente: Elaborado con datos de la Oficina de Análisis Económico del Departamento de Comercio de los Estados Unidos.

y las remesas de inmigrantes; uno de los aciertos del gobierno de Vicente Fox fue mejorar el perfil de la deuda externa, lo que junto con una reserva monetaria internacional que llegó a rebasar los US $\$ 80000$ millones otorgaba solidez al tipo de cambio que se movía en una banda de entre $\$ 10.70$ y $\$ 11.50$ por dólar.

Un problema persistente era el de la inflación: desde hacía varios años el Banco Central luchaba por lograr una meta de alrededor de 3\%. En su anuncio de política monetaria del 18 de enero de 2008, el Banxico reconocía que desde 2006 los precios internacionales de los alimentos habían estado sujetos a presiones que hasta ese momento no habían logrado contaminar las expectativas inflacionarias.

El desenvolvimiento de la crisis financiera en los Estados Unidos se expresó en un cambio de dirección de los capitales internacionales, de los bonos y las acciones a los metales y las materias primas, especialmente el oro ${ }^{33}$ y el petróleo ${ }^{34}$. Como resultado se incrementó el precio internacional del crudo, las gasolinas y las materias primas y los metales.

33 Como resultado de la fuerte demanda del oro por parte de inversionistas que buscaron refugio ante la caída del dólar, el precio de la onza de oro pasó de los US \$560 el 6 de octubre de 2006 a US $\$ 995$ el 13 de marzo de 2008.

34 En 2006, el precio promedio del barril de petróleo West Texas Intermediate (WTI) fue de US \$ 66.15 por barril; en 2008 el precio promedio ascendió a US \$105.09.

\section{Desarrollo}


Así, México experimentó un aceleramiento de la inflación ${ }^{35}$ debido a los alimentos, las materias primas, los metales y especialmente las gasolinas. Ello significó que no pudiera producirse el esperado relajamiento de la política monetaria, al contrario, el Banco Central de México incrementó el objetivo de la tasa interbancaria a un día en 75 pb: de $7.5 \%$ en febrero de 2008 a $8.25 \%$ en noviembre de $2009^{36}$.

La inflación internacional, en gran medida generada por el malestar financiero estadounidense, desalineó las políticas monetarias de los EEUU y México: mientras en aquel país comenzó un agresivo ciclo de descenso de tasas de interés, en México éstas se incrementaron, elevándose el diferencial de tasas entre estos dos países. En la gráfica 3 puede observarse el comportamiento de las tasas de referencia de los bancos centrales de México y los EEUU, así como el correspondiente diferencial.

Gráfica 3

Tasas de referencia de los bancos centrales México-Estados Unidos agosto de 2007 a julio de 2009

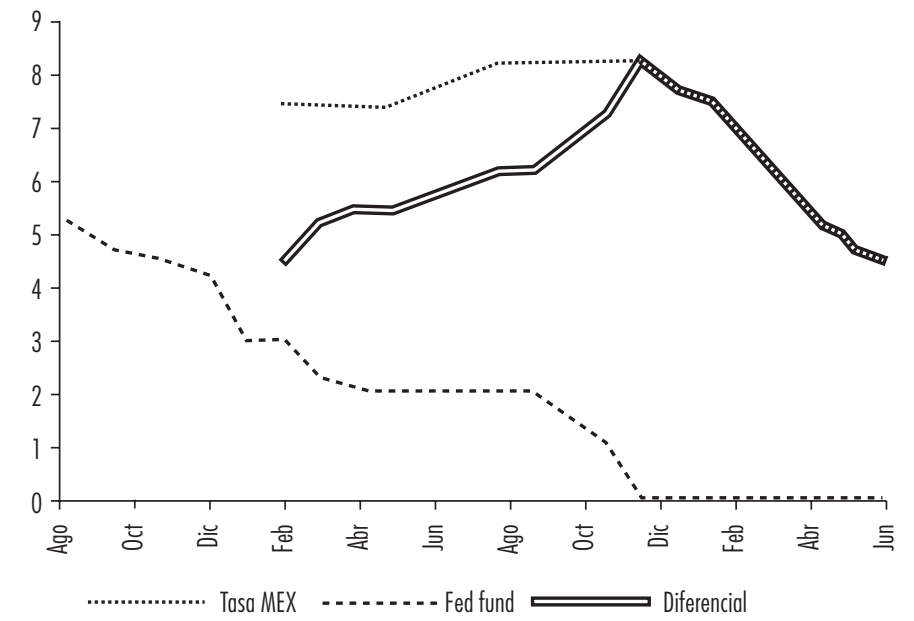

Fuente: Elaboración propia con datos de Banco de México y de la Reserva Federal.

El diferencial de tasas se incrementó entre febrero y diciembre de 2008; para 2009 un ciclo de bajadas de la tasa de referencia del Banco de México comenzó a reducir dicho diferencial.

35 En octubre de 2007, la inflación mensual anualizada fue de 3.74\%, pero después de ese mes fue creciendo sostenidamente hasta llegar a un pico de $6.53 \%$ en diciembre de 2008 , muy lejos de la meta oficial de un máximo de cuatro por ciento.

36 El 21 de enero de 2008 comienza a operar en México una política monetaria centrada en un objetivo para la Tasa Interbancaria a un día. Este mecanismo sustituyó al corto monetario. 
Los movimientos del peso mexicano coinciden con el comportamiento del diferencial de tasas, en tanto éste aumentaba el peso se apreció fuertemente desde los $\$ 10.79$ del 21 de febrero de 2008 hacia los $\$ 9.8745$ el 4 de agosto de ese mismo año; cuando el diferencial de tasas cambió de tendencia, el peso comenzó una depreciación que terminó siendo brutal, hasta los \$15.49 por dólar el 9 de marzo de 2009. En la gráfica 4 puede observarse la magnitud de la depreciación cambiaria.

Gráfica 4

Pesos por dolar, México. 02/01/2008 a 02/01/2009

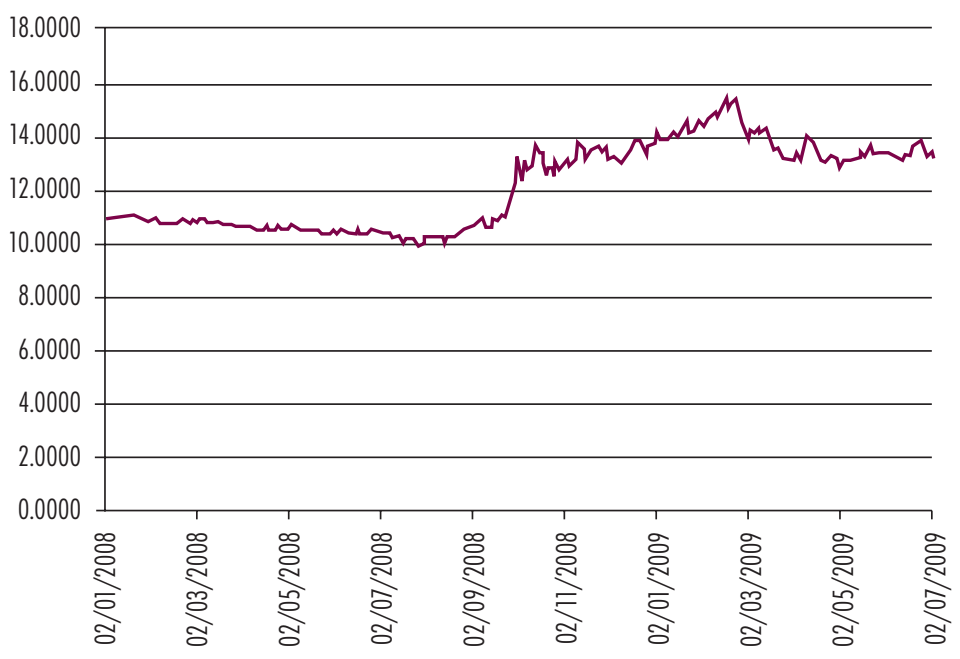

Fuente: Elaboración propia con datos de Banco de México.

Visto desde el otro lado de la moneda, el ciclo de apreciación y depreciación del peso mexicano revela el correspondiente ciclo de debilitamiento-recuperación del dólar a escala internacional.

Efectivamente, el desplome de los mercados de bonos y acciones estadounidenses llevó a una burbuja especulativa en los mercados del oro y del petróleo; cuando esta burbuja se rompió, especialmente en el mercado petrolero, los capitales volvieron a buscar la seguridad de los Bonos del Tesoro americano, robusteciendo el valor del dólar.

De tal manera sucedieron las cosas que aquellos factores que habían fortalecido al peso, se revirtieron: el diferencial de tasas entre los EEUU y México dejó de aumentar para finalmente empezar a reducirse; los capitales salieron de mercados sobrecomprados como el oro y el petróleo, así como de los mercados emergentes buscando nuevamente la seguridad de los Bonos del Tesoro americano; la difícil situación de los sistemas bancarios estadounidense y europeo se expresó en una falta de liquidez

\section{Desarrollo}


mundial de dólares y, finalmente, se comenzaron a cerrar las fuentes de generación de dólares para la economía mexicana, a saber, las exportaciones, las remesas de inmigrantes y la inversión extranjera. La depreciación del peso entre agosto de 2008 y marzo de 2009 tuvo como característica la presencia de una gran volatilidad ${ }^{37}$ (véase gráfica 5).

Gráfica 5

Volatilidad del tipo de cambio. México. 02/01/2007 al 10/07/2009

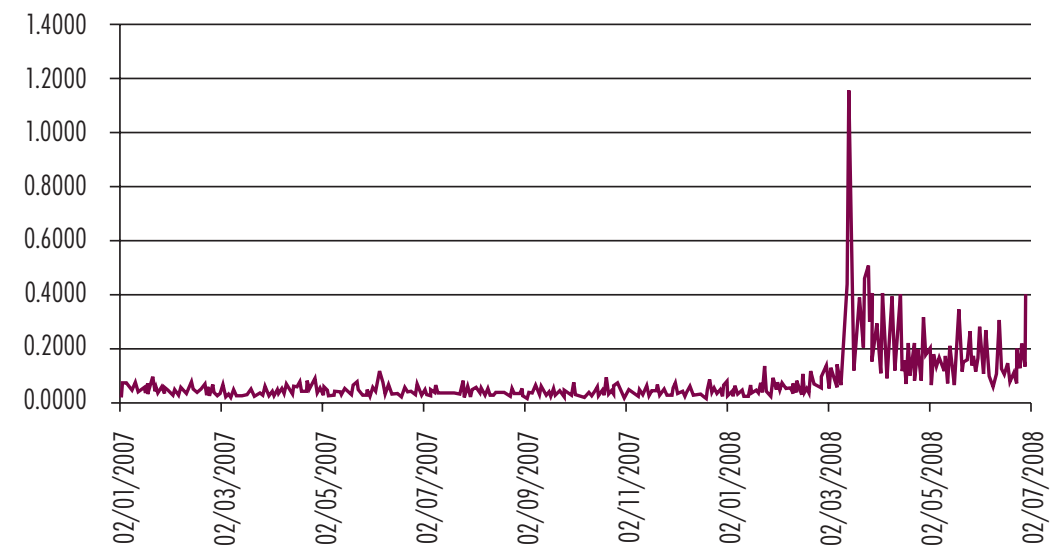

Fuente: Elaboración propia con datos de Banco de México.

Por su parte, el índice de las acciones mexicanas ha seguido un comportamiento similar al del Dow Jones. En la gráfica 6 podemos observar el comportamiento del Índice de Precios y Cotizaciones (IPC) de la Bolsa Mexicana de Valores, entre enero de 2004 y marzo de 2009.

Entre 2005 y 2007 se da un movimiento de alza (bull) de larga duración que termina por llevar al IPC a un máximo histórico de 32836.12 puntos el día 18 de octubre de 2007. Este movimiento puede observarse en promedio móvil (PM 90) ascendente que se presenta en la gráfica.

También, al igual que en el caso del Dow Jones, se desarrolla una fase técnica de lateralidad en un canal muy amplio entre los 32836.12 y los 25284.88 puntos que se alcanzan el 21 de enero de 2008. Este canal de lateralidad o rectángulo queda delimitado por las dos líneas horizontales que se marcan en la gráfica 6.

Precisamente en este último nivel, en que el IPC toca territorio bear, se sustenta

37 La volatilidad se mide como la diferencia entre el precio máximo y el precio mínimo en el tipo de cambio diario spot 48 horas según lo registra el Banco de México. 
Gráfica 6

Índice de Precios y Cotizaciones (IPC), México

enero de 2004 a marzo de 2005

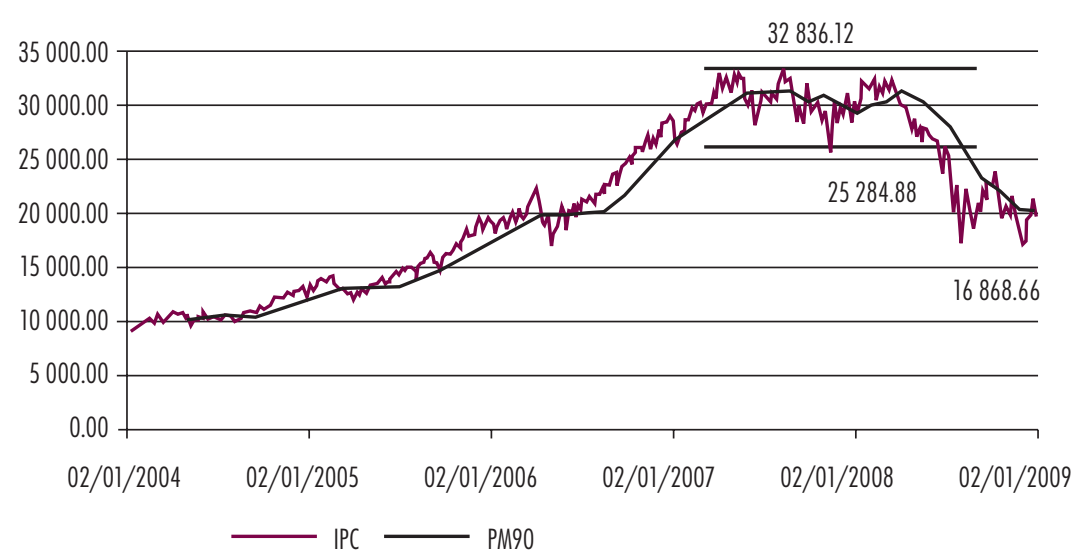

Fuente: Elaboración con datos del Banco de México.

una recuperación, de la mano del Dow Jones, por el efecto de la política monetaria de la Reserva Federal. La recuperación lleva al IPC al nivel de 31726.01 puntos el 5 de junio de 2008.

En la gráfica puede observarse que en el rectángulo marcado por las dos líneas horizontales, el IPC forma una figura de doble cima, que es considerada como una figura de cambio en la tendencia primaria, en este caso de alza (bull) a baja (bear).

El cambio de tendencia se confirma una vez que el IPC rompe a la baja el rectángulo de lateralidad. A partir de entonces, el IPC se precipita en un descenso bear que finalizó con un crack a nivel de los 16868.66 puntos el día 27 de octubre de 2008. El nivel de 16868 puntos en el Índice de Precios y Cotizaciones se constituyó en un soporte sólido que marcó el fondo de la crisis financiera.

La crisis financiera, tanto en los EEUU como en México, tuvo la violencia suficiente para afectar los fundamentos económicos y precipitar sendas recesiones.

\section{La recesión económica en México}

México, por su parte, ha sido una economía altamente dependiente de su contraparte norteamericana; a raíz del TLC las exportaciones han sido el componente más importante del Producto Interno Bruto, así que cuando la producción estadounidense comenzó a relajarse, tanto las exportaciones como las importaciones mexicanas comenzaron su descenso; estos dos agregados empezaron a caer en el primer trimestre de 2008 (véase gráfica 7), revelando la atonía en la que estaba entrando la producción.

\section{Desarrorollo}


La recesión mexicana fue reconocida oficialmente en abril de $2009^{38}$.

Gráfica 7

Exportaciones e importaciones de México (millones de dólares). 2006-I a 2009-III

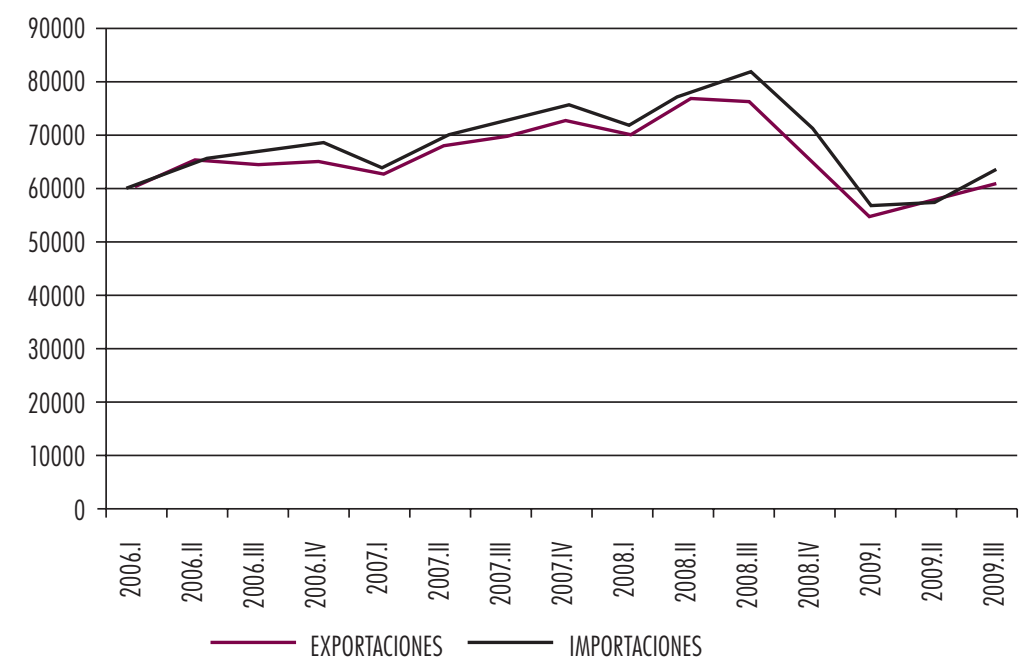

Fuente: Elaborado con datos del INEGI.

Evidentemente, la desaceleración económica hasta niveles recesivos ha afectado los niveles de empleo (véase gráfica 8). El incremento de la tasa de desocupación en los EEUU y México ha coincidido con el derrumbe de sus correspondientes mercados accionarios en la segunda mitad de 2008, lo que significó el deterioro acelerado de las expectativas económicas.

Hemos señalado que en el plano financiero la crisis americana significó la quiebra y desaparición de la banca de inversión, así como un fuerte debilitamiento de la banca comercial; en el plano económico la crisis ha significado el derrumbe de su industria automotriz, representada por las tres grandes de Detroit, a saber, Ford, General Motors (GM) y Chrysler ${ }^{39}$. Estas tres empresas, cuya bonanza se sustentó en el fuerte

38 La recesión económica mexicana comenzó en el cuarto trimestre de 2008 con una caída del PIB de $-0.6 \%$ anualizado, se aceleró en el primer trimestre de 2009 con una caída de $-8 \%$ y una de $-10 \%$ en el segundo trimestre de 2009. Se prevé que la caída anual de 2009 superará el $7 \%$, rebasando así a la caída de la producción experimentada en la recesión de 1995.

39 A pesar de que se han destinado fuertes sumas de dinero gubernamental a las empresas automotrices, Chrysler y GM entraron en proceso de quiebra; Ford se sometió a un severo proceso de reestructuración para poder sortear la debilidad del mercado americano. 
Gráfica 8

Tasas de desocupación anualizadas. México y Estados Unidos enero de 2007 a julio de 2009

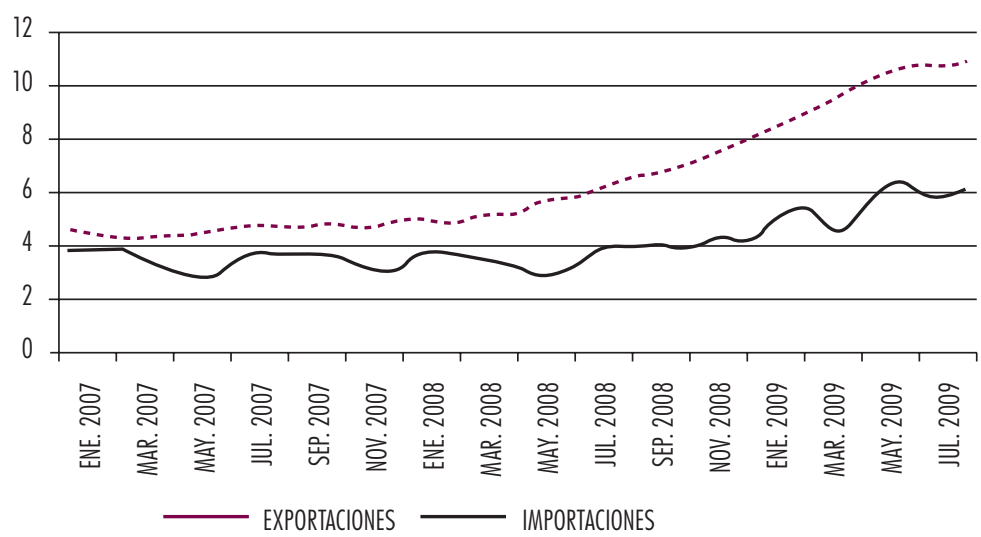

Fuente: Elaborado con datos del INEGI.

consumo de los norteamericanos, cayeron en desgracia cuando los consumidores fueron castigados con el desempleo y la pérdida de ingresos y riqueza.

La precaria situación del sector automotor americano ha tenido nefasta manifestación en México ${ }^{40}$ : las exportaciones de automóviles y autopartes a ese país ${ }^{41}$ se han reducido de manera drástica, afectando negativamente la actividad productiva de las plantas armadoras de autos así como la de sus empresas proveedoras.

El lunes 23 de febrero de 2009, General Motors anunció el cierre de tres plantas en México ${ }^{42}$, debido a una reducción de la demanda tanto en el mercado americano como internamente ${ }^{43}$. Entre febrero y marzo de 2009, GM despidió a 600 trabajadores de su planta en Ramos Arizpe, Guanajuato. Ford cerró temporalmente su planta en Cuautitlán Izcalli ${ }^{44}$, Estado de México, lo que ha significado el despido de 600 trabajadores.

La crisis también ha significado el cierre de las oportunidades laborales de los inmigrantes ilegales mexicanos, afectando doblemente al país: por la caída del flujo de

40 La industria automovilística representa poco más de 3\% del PIB.

41 El 81\% de las exportaciones de manufacturas mexicanas tiene como destino los EEUU. El 27\% de estas exportaciones corresponde a automóviles (16\%) y autopartes (11 por ciento).

42 Las plantas de Silao y Guanajuato pararían cinco días en marzo; dos líneas de producción en la planta de Ramos Arizpe pararían seis días en el mismo mes.

43 Las exportaciones automotrices se hundieron $57 \%$ en enero, en tanto que las ventas nacionales cayeron 28 por ciento.

44 La planta se remodela para la fabricación del nuevo modelo Ford Fiesta a partir de octubre de 2010.

\section{DeSarrollo}


dólares por remesas y porque se ha cerrado la válvula de escape a la presión interna del desempleo.

La recesión económica en México, que inició en el cuarto trimestre de 2008, todavía está en fase de expansión: desde los sectores exportadores hacia las actividades industriales y el resto de la economía; se prevé que la recesión concluya en el segundo trimestre de 2009, sin que ello signifique que la recuperación sea sólida y sostenida.

Las características de esta crisis permiten pensar que el desempleo será más intenso y prolongado que en crisis pasadas. Es poco previsible una recuperación de la demanda estadounidense con la celeridad y fortaleza requeridas para reimpulsar la actividad exportadora de nuestro país. En este mismo sentido, la naturaleza global de la crisis hace difícil sustituir el mercado americano por otros mercados en el mundo. Por otro lado, el gobierno mexicano se ha visto sumido en un letargo que le ha impedido llevar a cabo programas para impulsar la demanda interna, esto es, en el contexto de una política económica conformista, el desempleo se ha traducido en una caída del dinamismo del mercado interno sin que se observen atenuantes en el mediano plazo. También, como se ha mencionado, la válvula de escape a la falta de oportunidades laborales en nuestro país, a saber, la emigración ilegal a los Estados Unidos, se ha cerrado.

El caso de México es particularmente dramático: ha sido una de las economías más afectadas por el fenómeno recesivo mundial toda vez que ha develado la fragilidad de las finanzas públicas, lo que a su vez está poniendo en tela de juicio la calificación crediticia del país.

\section{Conclusión}

El modelo Minsky-Kindleberger nos ha permitido interpretar las crisis de los Estados Unidos y México, vistas a través de sus respectivos índices accionarios: el Dow Jones Industrial Average y el Índice de Precios y Cotizaciones.

En los Estados Unidos, la crisis financiera se ha desarrollado en todas la fases previstas por el modelo, desde la fase de desplazamiento hasta la de recesión económica.

La intervención de la Reserva Federal americana, mediante las inyecciones de liquidez y una política de rebaja de la tasa de los fondos federales, si bien no evitó el crack bursátil ni la recesión, sí logró mitigar la profundidad de esos eventos. Digamos que en esta ocasión, la función de prestamista de última instancia que ejerció la Fed logró desarmar la quiebra del sistema financiero mundial y la depresión económica. No obstante, la crisis americana deja algunas lecciones muy importantes.

La especulación es un ingrediente básico del sistema económico mundial actual, hay razones para ello: la libertad financiera global, el predominio de regímenes cam- 
biarios flotantes, la altísima liquidez en los mercados internacionales de capital; la alta capacidad de innovación en las telecomunicaciones; las filosofías administrativas orientadas a incrementar el valor de mercado de las firmas; las políticas monetarias incorrectas o al menos imprecisas; la existencia de desequilibrios en los países, especialmente en los Estados Unidos, entre algunas otras.

La especulación financiera ha sido el ingrediente básico en el ciclo de expansióncontracción del sistema económico estadounidense. En un contexto de regulación financiera deficiente, fue capaz de crear los instrumentos para financiarizar activos reales, expandir la liquidez y el crédito.

La financiarización de activos reales vincula el ciclo financiero y el ciclo económico de manera natural. Un boom financiero implica una expansión de la economía; por el contrario, la caída del valor de los activos financieros afecta las variables económicas al grado de poder generar la recesión.

El comportamiento especulativo es bastante inercial, por ello lleva las variables a niveles de sobrerreacción, ya sea al alza o a la baja, pero esta sobrerreacción inherentemente tiende a corregirse. En este sentido, la especulación lleva el precio de los activos financieros y reales a niveles que alcanzan la ficción. Lo lamentable del asunto es que en la economía americana se tomaron decisiones de asignación de recursos sobre la base de estos precios ficticios, específicamente la inversión y el consumo.

El comportamiento inercial de los agentes económicos y de las mismas autoridades se debió a la rigidez de sus expectativas; en este sentido, la política monetaria fue sólo reactiva e imprecisa.

El exceso de inversión en la economía real y la especulación financiera tienen un límite temporal en el que necesariamente se revierten, este limite queda determinado cuando se agotan las oportunidades de inversión factibles, en ese punto, la sobreinversión se convierte en un obstáculo para la expansión. Por eso, la crisis financiera y la consecuente recesión desempeñan una función profiláctica, al eliminar la riqueza ficticia creada en los mercados financieros y ajustar las pautas de inversión.

La crisis, tanto en su parte financiera como económica, puede ser muy violenta, dependiendo de la magnitud de la sobreinversión; es aquí cuando alcanza relevancia la intervención de las autoridades monetarias. Esta intervención, en la medida necesaria, detendrá la crisis y finalmente contribuirá a la estabilización. No sin asumir los riesgos contemplados en las masivas inyecciones de liquidez.

Las lecciones que deja la crisis estadounidense permiten poner el acento en la importancia de una reforma al sistema monetario internacional, que tenga como estrategia fundamental eliminar o al menos acotar los márgenes de la actividad espe- 
culativa. Muchos son los temas de una agenda reformista, entre ellos, la regulación financiera, una política monetaria proactiva, el control de los déficit de los países, un sistema sustentable de monedas de reserva y el control a los movimientos especulativos de capital.

\section{Bibliografía}

Álvarez González, Alfonso, Análisis bursátil con fines especulativos: un enfoque moderno, México, Limusa, 2005.

Departamento de Análisis de Deuda Privada de IXE Grupo Financiero, Bursatilizaciones de Hipotecas, en http://www.ixe.com.mx/ storage/MBS\%-tutorial.pdf

El financiero, México, 17 de diciembre de 2007; 7 de octubre de 2008; 6 de noviembre de 2008; 7 de noviembre de 2008.

Gómez-Tagle Rangel, Rocío, "Lecciones para México tras el financiamiento subprime en EU", El financiero, México, lunes 17 de diciembre de 2007.

Grado de riesgo de inversión en países de economía emergente, en http://www.mexicomaxico.org/Voto/Riesgo.htm

Indicadores diarios de la Bolsa Mexicana de Valores, en http://www.banxico.org.mx/ sistemafinanciero/estadisticas/MercadoDineroValores/valoresCirculacion.html

INEGI, Tasa de desocupación, países seleccionados, en http://dgcnesyp.inegi.org.mx/ cgi-win/bdiecoy.exe/575=

Kindleberger, Charles P., El orden económico internacional, Barcelona, Crítica, 1992.

La Caixa, Informe mensual, núm. 298, enero de 2007, en http://www.pdf.lacaixa.comunicacions.com/im/esp/200701aft.esp.pdf
Precios históricos, en http://mx.finance.yahoo. $\mathrm{com} / \mathrm{q} / \mathrm{hp}$ ? $\mathrm{s}=\% 5 \mathrm{EDJ}$

Sánchez Cantú, Leopoldo, Claudio Núñez Sánchez de la Barquera y Eduardo Couto Castillo, Invierta con éxito en la Bolsa de Valores, México, Pearson Educación, 2000.

Suárez-Vélez, Jorge, Inversión sin fronteras, La banca de cristal: lloviendo sobre mojado III, 8 de febrero de 2008, en http:// mx.pfinance.yahoo.com/inversion_sin_ fronteras/98/la-banca-de-cristal-lloviendosobre-mojado-iii

Stiglitz, Joseph E., Los felices 90. La semilla de la destrucción, México, Taurus, 2004.

The Federal Reserve Board, "Intended federal funds rate", Open Market Operations, en http://www.federalreserve.gov/fomc/fundsrate.htm

Tipo de cambio, pesos por dólar EUA (diario), en http://www.banxico.org.mx/Portales Especializados/tiposCambio/indicadores. html

U.S. Department of Commerce, Bureau of Economic Analysis, U.S. Economic Accounts, en http://www.bea.gov/

24hgold, Press Review Today, interactive chart, en http://www.24gold.com/english/home. aspx 
EL INSTITUTO DE INVESTIGACIONES ECONÓMICAS DE LA UNIVERSIDAD NACIONAL AUTÓNOMA DE MÉXICO

CONVOCA AL

\section{PREMIO ANUAL DE INVESTIGACIÓN ECONÓMICA MAESTRO JESÚS SILVA HERZOG 2010}

\section{VERSIÓN EXTERNA}

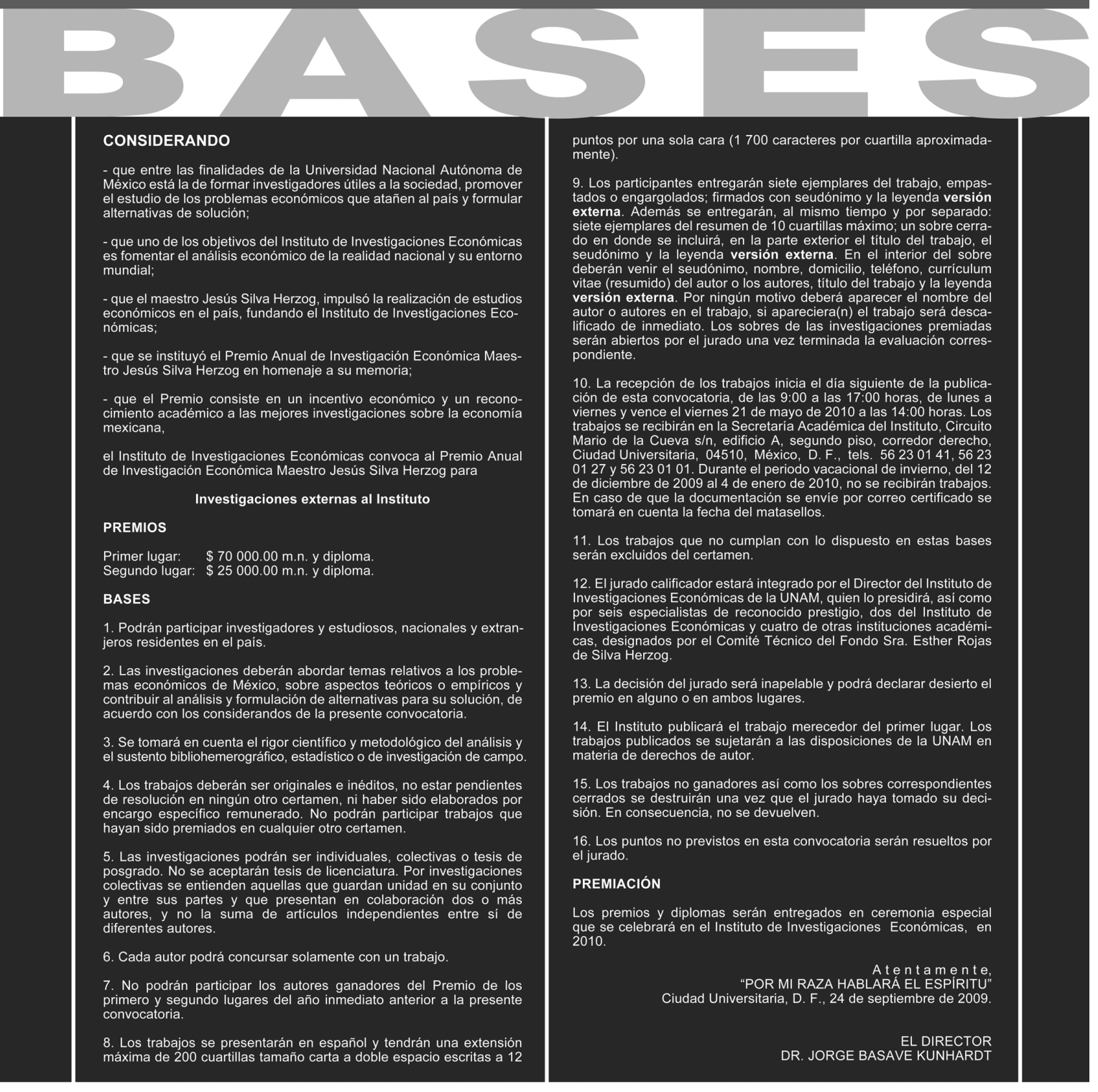

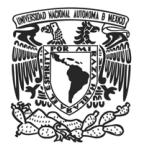

Consulte la presente Convocatoria en http://www.iiec.unam.mx

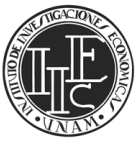

